\title{
DECLARACIÓN UNIVERSAL DE LOS DERECHOS HUMANOS (1948-1998)
}

\section{Naciones Unidas}

\section{ADOPTADA Y PROCLAMADA POR LA ASAMBLEA GENERAL DE LAS NACIONES UNIDAS EN SU RESOLUCIÓN 217A (III), DE 10 DE DICIEMBRE DE 1948}

\section{Preámbulo}

Considerando que el desconocimiento y el menosprecio de los derechos humanos han originado actos de barbarie ultrajantes para la conciencia de la humanidad; y que se ha proclamado, como la aspiración más elevada del hombre, el advenimiento de un mundo en que los seres humanos, liberados del temor y de la miseria, disfruten de la libertad de palabra y de la libertad de creencias,

Considerando esencial que los derechos humanos sean protegidos por un régimen de Derecho, a fin de que el hombre no se vea compelido al supremo recurso de la rebelión contra la tiranía y la opresión,

Considerando también esencial promover el desarrollo de relaciones amistosas entre las naciones,

Considerando que los pueblos de las Naciones Unidas han reafirmado en la Carta su fe en los derechos fundamentales del hombre, en la dignidad y el valor de la persona humana y en la igualdad de derechos de hombres y mujeres; y se han declarado resueltos a promover el progreso social y a elevar el nivel de vida dentro de un concepto más amplio de la libertad,

Considerando que los Estados Miembros se han comprometido a asegurar, en cooperación con la Organización de las Naciones Unidas, el respeto universal y efectivo a los derechos y libertades fundamentales del hombre, y

Considerando que una concepción común de estos derechos y libertades es de la mayor importancia para el pleno cumplimiento de dicho compromiso,

\section{La Asamblea General}

Proclama la presente Declaración Universal de Derechos Humanos como ideal común por el que todos los pueblos y naciones deben esforzarse, a fin de que tanto los individuos como las instituciones, inspirándose constantemente en ella, promuevan, mediante la enseñanza y la educación, el respeto a estos derechos y libertades, y aseguren, por medidas progresivas de carácter nacional e internacional, su reconocimiento y aplicación universales y efectivos, tanto entre los pueblos de los Estados Miembros como entre los de los territorios colocados bajo su jurisdicción.

\section{Artículo 1}

Todos los seres humanos nacen libres e iguales en dignidad y derechos y, dotados como están de razón y conciencia, deben comportarse fraternalmente los unos con los otros.

\section{Artículo 2}

1. Toda persona tiene los derechos y libertades proclamados en esta Declaración, sin distinción alguna de raza, color, sexo, idioma, religión, opinión política o de cualquier otra índole, origen nacional o social, posición económica, nacimiento o cualquier otra condición.

2. Además, no se hará distinción alguna fundada en la condición política, jurídica o internacional del país o territorio de cuya jurisdicción dependa una persona, tanto si se trata de un país independiente, como de un territorio bajo administración fiduciaria, no autónomo o sometido a cualquier otra limitación de soberanía.

\section{Artículo 3}

Todo individuo tiene derecho a la vida, a la libertad y a la seguridad de su persona.

\section{Artículo 4}

Nadie estará sometido a esclavitud ni a servidumbre; la esclavitud y la trata de esclavos están prohibidas en todas sus formas.

\section{Artículo 5}

Nadie será sometido a torturas ni a penas o tratos crueles, inhumanos o degradantes.

\section{Artículo 6}

Todo ser humano tiene derecho, en todas partes, al reconocimiento de su personalidad jurídica.

\section{Artículo 7}

Todos son iguales ante la ley y tienen, sin distinción, derecho a igual protección de la ley. Todos tienen derecho a igual protección contra toda discriminación que infrinja esta Declaración y contra toda provocación a tal discriminación. 


\section{Artículo 8}

Toda persona tiene derecho a un recurso efectivo, ante los tribunales nacionales competentes, que la ampare contra actos que violen sus derechos fundamentales reconocidos por la constitución o por la ley.

\section{Artículo 9}

Nadie podrá ser arbitrariamente detenido, preso ni desterrado.

\section{Artículo 10}

Toda persona tiene derecho, en condiciones de plena igualdad, a ser oída públicamente y con justicia por un tribunal independiente e imparcial, para la determinación de sus derechos y obligaciones o para el examen de cualquier acusación contra ella en materia penal.

\section{Artículo 11}

1. Toda persona acusada de delito tiene derecho a que se presuma su inocencia mientras no se pruebe su culpabilidad, conforme a la ley y en juicio público en el que se le hayan asegurado todas las garantías necesarias para su defensa.

2. Nadie será condenado por actos u omisiones que en el momento de cometerse no fueron delictivos según el Derecho nacional o internacional. Tampoco se impondrá pena más grave que la aplicable en el momento de la comisión del delito.

\section{Artículo 12}

Nadie será objeto de injerencias arbitrarias en su vida privada, su familia, su domicilio o su correspondencia, ni de ataques a su honra o a su reputación. Toda persona tiene derecho a la protección de la ley contra tales injerencias $\mathrm{o}$ ataques.

\section{Artículo 13}

1. Toda persona tiene derecho a circular libremente y a elegir su residencia en el territorio de un Estado.

2. Toda persona tiene derecho a salir de cualquier país, incluso el propio, y a regresar a su país.

\section{Artículo 14}

1. En caso de persecución, toda persona tiene derecho a buscar asilo, y a disfrutar de él, en cualquier país.

2. Este derecho no podrá ser invocado contra una acción judicial realmente originada por delitos comunes o por actos opuestos a los propósitos y principios de las Naciones Unidas.

\section{Artículo 15}

1. Toda persona tiene derecho a una nacionalidad.

2. A nadie se privará arbitrariamente de su nacionalidad ni del derecho a cambiar de nacionalidad.

\section{Artículo 16}

1. Los hombres y las mujeres, a partir de la edad núbil, tienen derecho, sin restricción alguna por motivos de raza, nacionalidad o religión, a casarse y fundar una familia; y disfrutarán de iguales derechos en cuanto al matrimonio, durante el matrimonio y en caso de disolución del matrimonio.
2. Sólo mediante libre y pleno consentimiento de los futuros esposos podrá contraerse el matrimonio.

3. La familia es el elemento natural y fundamental de la sociedad y tiene derecho a la protección de la sociedad y del Estado.

\section{Artículo 17}

1. Toda persona tiene derecho a la propiedad, individual y colectivamente.

2. Nadie será privado arbitrariamente de su propiedad.

\section{Artículo 18}

Toda persona tiene derecho a la libertad de pensamiento, de conciencia y de religión; este derecho incluye la libertad de cambiar de religión o de creencia, así como la libertad de manifestar su religión o su creencia, individual y colectivamente, tanto en público como en privado, por la enseñanza, la práctica, el culto y la observancia.

\section{Artículo 19}

Todo individuo tiene derecho a la libertad de opinión y de expresión; este derecho incluye el no ser molestado a causa de sus opiniones, el de investigar y recibir informaciones y opiniones, y el de difundirlas, sin limitación de fronteras, por cualquier medio de expresión.

\section{Artículo 20}

1. Toda persona tiene derecho a la libertad de reunión y de asociación pacíficas.

2. Nadie podrá ser obligado a pertenecer a una asociación.

\section{Artículo 21}

1. Toda persona tiene derecho a participar en el gobierno de su país, directamente o por medio de representantes libremente escogidos.

2. Toda persona tiene el derecho de acceso, en condiciones de igualdad, a las funciones públicas de su país.

3. La voluntad del pueblo es la base de la autoridad del poder público; esta voluntad se expresará mediante elecciones auténticas que habrán de celebrarse periódicamente, por sufragio universal e igual y por voto secreto u otro procedimiento equivalente que garantice la libertad del voto.

\section{Artículo 22}

Toda persona, como miembro de la sociedad, tiene derecho a la seguridad social, y a obtener, mediante el esfuerzo nacional y la cooperación internacional, habida cuenta de la organización y los recursos de cada Estado, la satisfacción de los derechos económicos, sociales y culturales, indispensables a su dignidad y al libre desarrollo de su personalidad.

\section{Artículo 23}

1. Toda persona tiene derecho al trabajo, a la libre elección de su trabajo, a condiciones equitativas y satisfactorias de trabajo y a la protección contra el desempleo.

2. Toda persona tiene derecho, sin discriminación alguna, a igual salario por trabajo igual.

3. Toda persona que trabaja tiene derecho a una remuneración equitativa y satisfactoria, que le asegure, así como a su familia, una existencia conforme a la dignidad humana 
y que será completada, en caso necesario, por cualesquiera otros medios de protección social.

4. Toda persona tiene derecho a fundar sindicatos y a sindicarse para la defensa de sus intereses.

\section{Artículo 24}

Toda persona tiene derecho al descanso, al disfrute del tiempo libre, a una limitación razonable de la duración del trabajo y a vacaciones periódicas pagadas.

\section{Artículo 25}

1. Toda persona tiene derecho a un nivel de vida adecuado que le asegure, así como a su familia, la salud y el bienestar, y en especial la alimentación, el vestido, la vivienda, la asistencia médica y los servicios sociales necesarios; tiene asimismo derecho a los seguros en caso de desempleo, enfermedad, invalidez, viudez, vejez y otros casos de pérdida de sus medios de subsistencia por circunstancias independientes de su voluntad.

2. La maternidad y la infancia tienen derecho a cuidados y asistencia especiales. Todos los niños, nacidos de matrimonio o fuera de matrimonio, tienen derecho a igual protección social.

\section{Artículo 26}

1. Toda persona tiene derecho a la educación. La educación debe ser gratuita, al menos en lo concerniente a la instrucción elemental y fundamental. La instrucción elemental será obligatoria. La instrucción técnica y profesional habrá de ser generalizada; el acceso a los estudios superiores será igual para todos, en función de los méritos respectivos.

2. La educación tendrá por objeto el pleno desarrollo de la personalidad humana y el fortalecimiento del respeto a los derechos humanos y a las libertades fundamentales; favorecerá la comprensión, la tolerancia y la amistad entre todas las naciones y todos los grupos étnicos o religiosos; y promoverá el desarrollo de las actividades de las Naciones Unidas para el mantenimiento de la paz.

3. Los padres tendrán derecho preferente a escoger el tipo de educación que habrá de darse a sus hijos.

\section{Artículo 27}

1. Toda persona tiene derecho a tomar parte libremente en la vida cultural de la comunidad, a gozar de las artes y a participar en el progreso científico y en los beneficios que de él resulten.

2. Toda persona tiene derecho a la protección de los intereses morales materiales que le correspondan por razón de las producciones científicas, literarias o artísticas de que sea autora.

\section{Artículo 28}

Toda persona tiene derecho a que se establezca un orden social e internacional en el que los derechos y libertades proclamados en esta Declaración se hagan plenamente efectivos.

\section{Artículo 29}

1. Toda persona tiene deberes respecto a la comunidad, puesto que sólo en ella puede desarrollar libre y plenamente su personalidad.

2. En el ejercicio de sus derechos y en el disfrute de sus libertades, toda persona estará solamente sujeta a las limitaciones establecidas por la ley con el único fin de asegurar el reconocimiento y el respeto de los derechos y libertades de los demás, y de satisfacer las justas exigencias de la moral, del orden público y del bienestar general en una sociedad democrática.

3. Estos derechos y libertades no podrán en ningún caso ser ejercidos en oposición a los propósitos y principios de las Naciones Unidas.

\section{Artículo 30}

Nada en la presente Declaración podrá interpretarse en el sentido de que confiere derecho alguno al Estado, a un grupo o a una persona, para emprender y desarrollar actividades o realizar actos tendientes a la supresión de cualquiera de los derechos y libertades proclamados en esta Declaración.

Alto Comisionado para los Derechos Humanos Centro de Derechos Humanos Palacio de las Naciones, 211

Ginebra $10-\mathrm{CH}$

Tel: 0041-22-917-34-56

Fax: 0041-22-91702-13 


\begin{tabular}{|c|c|c|c|c|c|c|c|c|}
\hline \multicolumn{9}{|c|}{ TRATADOS INTERNACIONA LES DE DERECHOS HUMANOS } \\
\hline $\begin{array}{l}\text { Estados } \\
\text { Parte }\end{array}$ & $\begin{array}{l}\text { Pacto } \\
\text { Internacional } \\
\text { de Derechos } \\
\text { Políticos y } \\
\text { Civiles } \\
\text { (PIDCP) }\end{array}$ & $\begin{array}{l}\text { Protocolo } \\
\text { Facultativo } \\
\text { del PIDCP }\end{array}$ & \begin{tabular}{|l|} 
Segundo \\
Protocolo \\
Facultativo \\
del PIDCP \\
relativo a la \\
abolición \\
de la pena \\
de muerte \\
\end{tabular} & \begin{tabular}{|l} 
Pacto \\
Internacional \\
de Derechos \\
Económicos, \\
Sociales y \\
Culturales \\
\\
\end{tabular} & \begin{tabular}{|l|} 
Convención \\
contra la \\
Tortura y otros \\
Tratos o penas \\
crueles, \\
Inhumanos o \\
Degradantes \\
\end{tabular} & \begin{tabular}{|l} 
Convención \\
sobre el \\
Estatuto \\
de los \\
Refugiados \\
$(1951)$
\end{tabular} & $\begin{array}{l}\text { Protocolo } \\
\text { sobre el } \\
\text { Estatuto de } \\
\text { los } \\
\text { Refugiados }\end{array}$ & $\begin{array}{l}\text { Convención } \\
\text { sobre la } \\
\text { Elimación de } \\
\text { Todas las } \\
\text { Formas de } \\
\text { Discriminación } \\
\text { contra la Mujer }\end{array}$ \\
\hline Argentina & $\mathrm{x}$ & $\mathrm{x}$ & & $\mathrm{x}$ & $\mathrm{x}(22)$ & $\mathrm{x}$ & $\mathrm{x}$ & \\
\hline Bahamas & & & & & & $\mathrm{x}$ & $x$ & \\
\hline Barbados & $\mathrm{x}$ & $\mathrm{x}$ & & $x$ & & & & \\
\hline Belice & $x$ & & & & $x$ & $\mathrm{x}$ & $x$ & \\
\hline Bolivia & $x$ & $\mathrm{x}$ & & $\mathrm{x}$ & $\mathrm{F}$ & $\mathrm{x}$ & $x$ & \\
\hline Brasil & $x$ & & & $x$ & $\mathrm{x}$ & $x$ & $x$ & \\
\hline Canadá & $x$ & $\mathrm{x}$ & & $x$ & $x(22)$ & $x$ & $x$ & \\
\hline Chile & $x$ & $x$ & & $x$ & $\mathrm{x}$ & $x$ & $x$ & \\
\hline Colombia & $x$ & $x$ & $x^{*}$ & $x$ & $x$ & $x$ & $x$ & \\
\hline Costa Rica & $x$ & $x$ & $\mathrm{~F}$ & $x$ & $x$ & $x$ & $x$ & \\
\hline Cuba & & & & & $x$ & & & \\
\hline Dominica & $x$ & & & $x$ & & $\mathrm{x}$ & $\mathrm{x}$ & \\
\hline Ecuador & $\mathrm{x}$ & $\mathrm{x}$ & $\mathrm{x}$ & $\mathrm{x}$ & $\mathrm{x}$ & $\mathrm{x}$ & $\mathrm{x}$ & \\
\hline El Salvador & $x$ & $\mathrm{x}$ & & $\mathrm{x}$ & $\mathrm{x}$ & $\mathrm{x}$ & $\mathrm{x}$ & \\
\hline $\begin{array}{l}\text { Estados } \\
\text { Unidos } \\
\end{array}$ & $\mathrm{x}$ & & & $\mathrm{F}$ & $\mathrm{x}$ & & $\mathrm{x}$ & \\
\hline Granada & $x$ & & & $\mathrm{x}$ & & & & \\
\hline Guatemala & $x$ & & & $x$ & $x$ & $\mathrm{x}$ & $x$ & \\
\hline Guyana & $x$ & $\mathrm{x}$ & & $x$ & $x$ & & & \\
\hline Haiti & $x$ & & & & & $x$ & $x$ & \\
\hline Honduras & $\mathrm{F}$ & $\mathrm{F}$ & & $\mathrm{x}$ & $\mathrm{x}$ & $x$ & $x$ & \\
\hline Jamaica & $x$ & $x$ & & $x$ & & $\mathrm{x}$ & $\mathrm{x}$ & \\
\hline México & $x$ & & & $\mathrm{x}$ & $x$ & & & \\
\hline Nicaragua & $x$ & $\mathrm{x}$ & & $x$ & & $\mathrm{x}$ & $x$ & \\
\hline Panamá & $x$ & $x$ & $\mathrm{x}$ & $x$ & $x$ & $x$ & $x$ & \\
\hline Paraguay & $x$ & $x$ & & $x$ & $x$ & $x$ & $x$ & \\
\hline Perú & $x$ & $x$ & & $x$ & $x$ & $\mathrm{x}$ & $x$ & \\
\hline $\begin{array}{c}\text { República } \\
\text { Dominicana }\end{array}$ & $\mathrm{x}$ & $\mathrm{x}$ & & $\mathrm{x}$ & $\mathrm{F}$ & & $\mathrm{x}$ & \\
\hline \multicolumn{9}{|l|}{$\begin{array}{c}\text { San Cristobal } \\
\text { y Nevis }\end{array}$} \\
\hline $\begin{array}{c}\text { San Vicente } \\
\text { y las } \\
\text { Granadinas }\end{array}$ & $\mathrm{x}$ & $\mathrm{x}$ & & $\mathrm{x}$ & & $\mathrm{x}$ & & \\
\hline \multicolumn{9}{|l|}{ Santa Lucía } \\
\hline Surinam & $\mathrm{x}$ & $\mathrm{x}$ & & $\mathrm{x}$ & & $\mathrm{x}$ & $\mathrm{x}$ & \\
\hline $\begin{array}{c}\text { Trinidad y } \\
\text { Tobago }\end{array}$ & $x$ & $\mathrm{x}$ & & $\mathrm{x}$ & & & & \\
\hline Uruguay & $x$ & $x$ & $\mathrm{x}$ & $\mathrm{x}$ & $\mathrm{X}(22)$ & $\mathrm{x}$ & $\mathrm{x}$ & \\
\hline Venezuela & $\mathrm{x}$ & $\mathrm{x}$ & $\mathrm{x}$ & $\mathrm{x}$ & \begin{tabular}{|l|}
$X(22)$ \\
\end{tabular} & & $\mathrm{x}$ & \\
\hline \multicolumn{9}{|c|}{$\begin{array}{l}\text { La F indica que el pais ha firmado la Convención pero aún no lo ha ratificado. } \\
\text { La X indica que ele pais es parte, ya sea por ratificación o por adhesión. } \\
\text { El*indica que el país firmó o se convirtó en Estado parte en } 1997 \text {. } \\
\text { (22) indica que se ha efectuado la declaración prevista en el artículo } 22 \text {, reconociendo la competencia del Comité contra la Tortura para recibir y } \\
\text { examinar las denuncias de violaciones de la Convención enviadas a título individual. }\end{array}$} \\
\hline
\end{tabular}




\section{Organización de los ESTados AMERicanos (OEA)}

\begin{tabular}{|c|c|c|c|}
\hline Estados Parte & $\begin{array}{l}\text { Convención } \\
\text { Americana } \\
\text { sobre Derechos } \\
\text { Humanos (1969) } \\
\end{array}$ & $\begin{array}{l}\text { Convención Interamericana para } \\
\text { Prevenir y Sancionar la Tortura } \\
\text { (1985) }\end{array}$ & $\begin{array}{l}\text { Convención Interamericana sobre } \\
\text { la Desaparición Forzada de } \\
\text { Personas } \\
(1994)^{*}\end{array}$ \\
\hline Argentina & $\mathrm{x}(62)$ & $\mathrm{x}$ & $\mathrm{x}$ \\
\hline \multicolumn{4}{|l|}{ Bahamas } \\
\hline Barbados & $\mathrm{x}$ & & \\
\hline \multicolumn{4}{|l|}{ Belice } \\
\hline Bolivia & $x(62)$ & $\mathrm{F}$ & $\mathrm{F}$ \\
\hline Brasil & $\mathrm{x}$ & $\mathrm{x}$ & $\mathrm{F}$ \\
\hline \multicolumn{4}{|l|}{ Canadá } \\
\hline Chile & $\mathrm{x}(62)$ & $\mathrm{x}$ & $\mathrm{F}$ \\
\hline Colombia & $x(62)$ & $\mathrm{F}$ & $\mathrm{F}$ \\
\hline Costa Rica & $\mathrm{x}(62)$ & $\mathrm{F}$ & $\mathrm{x}$ \\
\hline \multicolumn{4}{|l|}{ Cuba } \\
\hline Dominica & $\mathrm{x}$ & & \\
\hline Ecuador & $x(62)$ & $\mathrm{F}$ & \\
\hline El Salvador & $\mathrm{x}(62)$ & $\mathrm{x}$ & \\
\hline $\begin{array}{c}\text { Estados Unidos } \\
\text { de América }\end{array}$ & $\mathrm{F}$ & & \\
\hline Granada & $\mathrm{x}$ & & \\
\hline Guatemala & $\mathrm{x}(62)$ & $\mathrm{x}$ & $\mathrm{F}$ \\
\hline \multicolumn{4}{|l|}{ Guyana } \\
\hline Haiti & $\mathrm{x}$ & $\mathrm{F}$ & \\
\hline Honduras & $\mathrm{x}(62)$ & $\mathrm{F}$ & $\mathrm{F}$ \\
\hline Jamaica & $\mathrm{x}$ & & \\
\hline México & $x$ & $X$ & \\
\hline Nicaragua & $\times(62)$ & $\mathrm{F}$ & $\mathrm{F}$ \\
\hline Panamá & $x(62)$ & $\mathrm{x}$ & $\mathrm{x}$ \\
\hline Paraguay & $\mathrm{x}(62)$ & $\mathrm{x}$ & $\mathrm{x}$ \\
\hline Perú & $\mathrm{x}(62)$ & $\mathrm{x}$ & \\
\hline $\begin{array}{l}\text { República } \\
\text { Dominicana }\end{array}$ & $\mathrm{x}$ & $\mathrm{x}$ & \\
\hline \multicolumn{4}{|l|}{$\begin{array}{c}\text { San Cristobal y } \\
\text { Nevis }\end{array}$} \\
\hline \multicolumn{4}{|l|}{$\begin{array}{c}\text { San Vicente y las } \\
\text { Granadinas }\end{array}$} \\
\hline \multicolumn{4}{|l|}{ Santa Lucía } \\
\hline Surinam & $\times(62)$ & $\mathrm{x}$ & \\
\hline Trinidad y Tobago & $\mathrm{x}(62)$ & & \\
\hline Uruguay & $\mathrm{x}(62)$ & $\mathrm{x}$ & $\mathrm{x}$ \\
\hline Venezuela & $\mathrm{x}(62)$ & $\mathrm{x}$ & $\mathrm{F}$ \\
\hline
\end{tabular}

La $\mathrm{F}$ indica que el país ha firmado la Convención pero aún no lo ha ratificado.

La X indica que el país es parte, ya sea por ratificación o por adhesión.

(62) indica que se ha realizado la declaración prevista en el artículo 62 por la que se reconoce como vinculante la competencia de la Corte Interamericana de Derechos Humanos (sobre todos los casos relativos a la interpretación o la aplicación de la Convención).

* Esta Convención entró en vigor el 29 de marzo de 1996.

En este cuadro figuran los países miembros de la OEA a fines de 1997.

Fuente: Amnistía Internacional: Informe 1998. Un año de promesas rotas. Edición y Traducción en Español. Madrid: Editorial Amnistía Internacional (EDAI) 


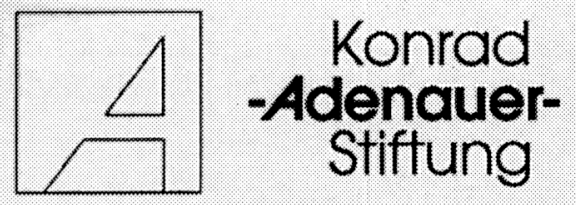

CIEDLA

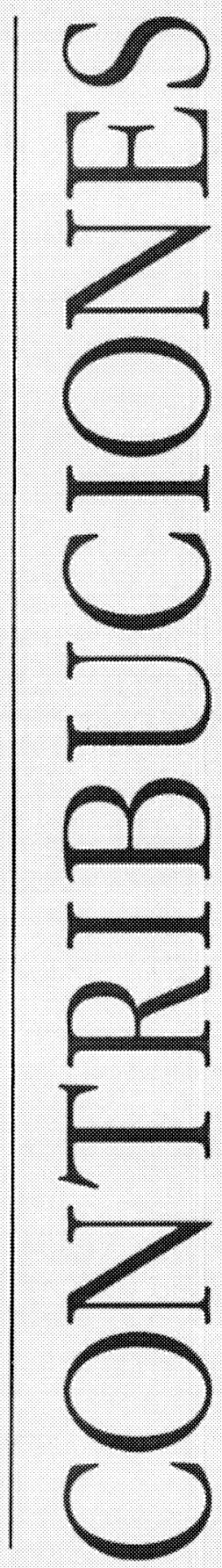

\section{Derechos Humanos:}

\section{ACTUALIDAD Y PERSPECTIVAS}

\section{TEMAS}

Declaración Universal de Derechos Humanos

La Declaración de los Derechos Humanos de las Naciones Unidas y su importancia para

América Latina

José Ayala Lasso

Los nuevos retos de la protección de los derechos

Francisco Fernández Segado

El sistema interamericano de promoción y protección de los derechos humanos

Carlos Ayala Corao

Los Defensores del Pueblo y los problemas de los Derechos Humanos en América Latina

Jorge Mario Garcia Laguardia

Los pueblos indigenas, derechos humanos y democracia en América Latina

Victor Hugo Cârdenas

\section{ENSAYOS}

La propuesta institucionalista frente al modelo neoclásico Cristina Hermida del Llano

América Latina como región de inversión y producción. Apreciaciones de los ejecutivos alemanes Heinrich-W. Krumwiede y Detlef Nolte

Inseguridad jurídica, pluralismo normativo y anomia social en América Latina

Peter Waldmann

\section{DOCUMENTOS Y HECHOS}

Reelección a la brasileña: las elecciones generales de 1998

David Fleischer 